\title{
On the Physical Composition of Solid Wastes in Selected Dumpsites of Ogbomosoland, South-Western Nigeria
}

\author{
Samson Ojoawo ${ }^{1}$, Oluwole Agbede ${ }^{2}$, Abimbola Sangodoyin ${ }^{3}$ \\ ${ }^{1}$ Department of Civil Engineering, Ladoke Akintola University of Technology, Ogbomoso, Nigeria \\ ${ }^{2}$ Department of Civil Engineering, University of Ibadan, Ibadan, Nigeria \\ ${ }^{3}$ Department of Agriculture and Environmental Engineering, University of Ibadan, Ibadan, Nigeria \\ E-mail: 'soojoawo@lautech.edu.ng, oluwoleagbede@yahoo.com,bimbo_sangodoyin@yahoo.co.uk \\ Received July 1, 2011; revised August 2, 2011; accepted September 3, 2011
}

\begin{abstract}
Solid wastes have varied compositions and constituents from place to place. The study area is not an exception. The entire 5 Local Government Area (LGA)s of Ogbomosoland were surveyed and about 40 major dumpsites were identified across the spread. Twenty-five (25) of these were selected, five (5) each per LGA, for the study. The wastes were collected from the dumps, sorted, weighed and classified according to their constituents. The densities of wastes from the 25 dumpsites were also determined. The overall average composition using the main classes of wastes were found to be food; $68.4 \%$, metals; $7.2 \%$, textile; $4.6 \%$, papers; $4.4 \%$, plastic; $3.9 \%$, glass; $3.6 \%$, wood; $3.1 \%$, and miscellaneous; $4.8 \%$. The average waste density for the study area was $438.1 \mathrm{~kg} / \mathrm{m}^{3}$. Putrescible materials dominated the waste composition of the study area. The components of wastes in the city revealed a higher standard of living when compared with those of the residents in the environs. Rural residents generate denser wastes when compared with the urban centres and as such are prone to leachate pollution emanating from these organic wastes. The ingress of leachate is a threat to the groundwater resources of the study area.
\end{abstract}

Keywords: Solid Wastes, Leachate, Pollution, Ogbomosoland

\section{Introduction}

Generally speaking, waste is an unwanted item or material but it has been tersely defined as an asset of negative value [1]. Waste stands for some undesirable products emanating from human activities. It is any material that is considered to be of no further use to the owner and is, hence, discarded. Waste is any unavoidable material generated from domestic activity or industrial operations for which there is no economic demand and, which must be disposed [2]. Waste, therefore, is any fluid or solid, which because of its quantity, physical, chemical or infectious nature can cause hazards to human health or environment when improperly treated, stored, transported or disposed of [3].

Waste is generated universally and is a direct consequence of all human activities. The general classification of waste is into solid, liquid and gaseous [4]. Gaseous waste is normally vented to the atmosphere either with or without treatment depending on composition and the specific regulations of the country in- volved. Liquid wastes (sewage, storm water, and sullage) are commonly discharged into sewers or water bodies or allowed to infiltrate into the ground.

Solid waste on the other hand, refers to non-liquid, non-soluble materials from municipal refuse to industrial wastes that contain complex and sometimes, hazardous substances. Solid waste also includes sewage sludge, agricultural refuse, construction demolition, and mining wastes [5]. Solid waste could mostly be referred to as an unwanted residual or semi-solid materials from industrial, commercial, agricultural and community operations. Solid wastes include items like garbage, tyres, appliances, combustible and non-combustible materials and contaminated soil that have been excavated. Solid wastes are not earth, clean soil, concrete, non-toxic fly ash or foundry sand.

Technically, solid waste is any material thick enough to be held by hand; thus liquids and gases in containers may be referred to as solid wastes. Solid waste is any substance in the material flow pattern, which is rejected by the society [6]. Wastes generated by the full extent of 
human activities range from relatively innocuous substances such as food and paper waste, to toxic substances such as paints, batteries, asbestos, healthcare wastes, sewage sludge and radioactive wastes [4]. Numerous classifications of solid wastes have been proposed [7], [8]. The following represents a simple classification of waste into broad categories according to its origin and risk to human and environmental health: household wastes; municipal wastes (MSW); commercial and nonhazardous industrial wastes; hazardous (toxic) industrial wastes; construction and demolition (C \& D) wastes; health care wastes (generated from health care facilities in hospitals and medical research centres); human, animal; and incinerator wastes.

Household wastes represent those generated in the home and collected by municipal waste collection services. Municipal Solid Waste (MSW) includes this plus shop and office waste, and food waste from restaurants also collected by municipal waste collection systems, plus waste derived from street cleaning, and green (organic) waste generated in parks and gardens. Hazardous wastes are materials considered waste, which are reactive (i.e. explosive), radioactive, corrosive, ignitable/ flammable and/or toxic in nature. The general public faces some hazards from these wastes. These include explosive hazard of solvents, petroleum, toxic chemicals used as pesticides, cleaning solutions, solvents, etc [6].

Radioactive substances are hazardous because prolonged exposure to ionization radiation often results in damage to living organisms, and the substances may persist over long periods of time [9]. Medical wastes are generally defined as solid wastes that are generated in diagnosis, treatment, or immunization of human beings or animals, including but not limited to: Soiled or bloodsoaked bandages; culture dishes and other glassware; discarded surgical instruments -scalpels; needles-used to give shots or draw blood; cultures, stocks, swabs used to inoculate cultures; removed body organs (tonsils, appendices, limbs); lancets-the little blade the doctor picks a finger with to get a drop of blood [10]. Human and animal wastes are usually not disposed of in landfills, although animal carcasses and waste from abattoirs may be found in some waste-dumps. Human corpses are not generally regarded as waste, but when buried they degrade in a similar way to other organic waste, and also produce leachate in significant quantities.

Solid waste composition, rate of generation and methods of treatment and disposal vary considerably throughout the world and largely determine the potential of waste to impair groundwater quality. Also, the rate at which waste is generated corresponds roughly with levels of income. In high-income countries of Europe and North America, between 500 and $750 \mathrm{~kg}$ of solid wastes are produced per person per year [11]. In contrast, urban populations in most low-income countries like Nigeria and Cote d'Ivoire, generate between 100 and 200 $\mathrm{kg}$ of solid waste per person per year [12]. Despite this lower rate, rapid urbanization, particularly in lowincome developing countries has left little space for disposal of the increasing amounts of waste material being generated in urban settings [13]. As a result, uncontrolled disposal i.e. "fly tipping" is rampant in many countries, and is a diffuse source of groundwater contamination.

The present study focuses mainly on the composition and constituents of wastes in the selected dumpsites of the 5 LGAs of Ogbomoso. The urban LGAs are Ogbomoso North and South while the rural ones are Oriire, Ogo Oluwa and Suurulere LGAs. The study also determined the waste densities.

\section{Methodology}

\subsection{Selected Dumpsites}

About forty (40) main dumpsites were identified in the study area out of which Twenty-five (25), 5 each were selected per LGA. Findings revealed that most of the dumpsites which were found too close to residential buildings were unauthorized by the Local Health Authorities. Again some of these dumpsites were located along the river courses and on undeveloped plots of lands. The dumps therefore serve as breeding places for the insects, flies, and rodents capable of spreading diseases like diarrhea, dysentery, typhoid and cholera (Plates I, II and III). The location, age and spread of the waste types in the selected dumpsites are presented in Tables $\mathbf{1}$ and $\mathbf{2}$.

\subsection{Instrumentation on Wastes Composition in the Dumpsites}

The tools, instruments and items employed included measuring tape, weighing balance, riffle box, portable waste bucket, hand-glove, rain-boot, rake, and spade.

\subsection{Site Preparation and Measurements}

The following steps were taken in determining the composition of wastes at the selected dumpsites:

1) $1 \mathrm{~m}^{2}$ portion of the dumpsites area was measured with the tape for the first trial.

2) The measured portion was raked and packed into a head-pan of pre-determined weight.

3) The waste in the head-pan was then measured by the use of weighing balance.

4) Sorting, separation, and categorization of waste materials in the head-pan were performed. 
Table 1. Classification of the dumpsites studied in Ogbomosoland.

\begin{tabular}{|c|c|c|c|c|}
\hline $\mathrm{S} / \mathrm{N}$ & Dumpsite Location & Age & Type of waste & LGA \\
\hline 1 & R.A Bello street, stadium area & 18 & Residential & Ogbomoso North \\
\hline 2 & Attenda abattoir & 19 & Industrial (Animal products) & “ \\
\hline 3 & Owode area & 15 & Commercial & “ \\
\hline 4 & SUB area, LAUTECH & 10 & Institutional & “ \\
\hline 5 & Masifa area & 13 & Residential & “ \\
\hline 6 & Aarada market & 20 & Commercial (Agricultural products) & Ogbomoso South \\
\hline 7 & Laka river bank & 18 & Residential & “ \\
\hline 8 & High School area & 13 & Institutional & “ \\
\hline 9 & Odokoto area & 12 & Residential & “ \\
\hline 10 & Adeleke sawmill & 10 & Industrial (Wood products) & “ \\
\hline 11 & Olorombo dumpsite & 14 & Residential & Oriire \\
\hline 12 & L.A primary school & 13 & Institutional & “ \\
\hline 13 & Behind Iluju market & 15 & Commercial & “ \\
\hline 14 & Adafila dumpsite & 11 & Agricultural & “ \\
\hline 15 & Ahoro Dada dumpsite & 12 & Residential & “ \\
\hline 16 & Ikolaba area dumpsite & 11 & Commercial (Agricultural products) & Ogo Oluwa \\
\hline 17 & Otamokun dumpsite & 15 & Residential & “ \\
\hline 18 & Behind Ajaawa Hotels & 12 & Residential & “ \\
\hline 19 & Iwo-Ate, behind Ile Baale & 10 & Residential & “ \\
\hline 20 & Lagbedu dumpsite & 14 & Agricultural & “ \\
\hline 21 & Behind central market, Iresa-Adu & 13 & Agricultural & Suurulere \\
\hline 22 & Dumpsite at Oko market area & 11 & Commercial & “ \\
\hline 23 & Behind Gambari motor park & 14 & Industrial (Automobile) & “ \\
\hline 24 & Behind primary school, Iresa-Apa & 14 & Institutional & “ \\
\hline 25 & Baaya Oje dumpsite & 12 & Agricultural & “ \\
\hline
\end{tabular}

Table 2 . The spread of waste types in the study area.

\begin{tabular}{|c|c|c|c|c|c|c|c|}
\hline \multirow{2}{*}{ LGA } & \multicolumn{3}{|c|}{ Industrial } & \multicolumn{3}{|c|}{ Domestic } & \multirow{2}{*}{ Total } \\
\hline & Agricultural & Automobile product & Wood product & Residential & Commercial & Institution & \\
\hline Ogbomoso North & 1 & - & - & 2 & 1 & 1 & 5 \\
\hline Ogbomoso South & - & - & 1 & 2 & 1 & 1 & 5 \\
\hline Oriire & 1 & - & - & 2 & 1 & 1 & 5 \\
\hline Ogo-Oluwa & 1 & - & - & 3 & 1 & - & 5 \\
\hline Suurulere & 2 & 1 & - & - & 1 & 1 & 5 \\
\hline
\end{tabular}


5) Each category of weight was weighed and recorded for all samples from selected dumpsites.

6) The results obtained were tabulated and the percent composition of each waste type was determined.

\subsection{Determination of Waste Density}

Waste density was determined using the riffle box, rake, spade, and hand-gloves. Wastes were packed into the cubical riffle box of dimension $0.3 \mathrm{~m} \times 0.3 \mathrm{~m} \times 0.3 \mathrm{~m}$ and tapped continuously until it was filled to capacity. The weight of the riffle box was determined before and after the filling. This enabled the determination of the mass of wastes contained in each of the box. Since the volume of the box had been determined as $0.027 \mathrm{~m}^{3}$, the density of waste was estimated from the ratio of its mass and volume. The exercise was then carried out in all the selected dumpsites in the study area.

Calculations:

Mass of the cubical form (Plank) $=2.50 \mathrm{~kg}$

Mass of wastes + cubical forms $=x \mathrm{~kg}$

Mass of wastes $=(x-2.50) \mathrm{kg}$

Volume of the cubical forms $\left(\mathrm{m}^{3}\right)=0.3 \times 0.3 \times 0.3=$ $0.027 \mathrm{~m}^{3}$

$$
\text { Density of wastes }=\frac{(x-2.50)}{0.027} \mathrm{~kg} / \mathrm{m}^{3}
$$

\section{Results and Discussion}

\subsection{Physical Composition of the Wastes}

The results of field work comprising the average values of the mass of wastes and their respective percent composition for the various LGAs are presented in Table 3. The putrescible components constitute about $70 \%$ of the wastes. The data show that the high proportion of biode- gradable component could be linked to traces of leachate pollution in both surface and underground water sources around the selected dumpsites. Higher values of metallic component (7.2\%) among the non-decomposable wastes could be attributed to some industrial activities in the study area such as automobile works, black and silver smith works, etc. Wood wastes were however intangible probably due to the fact that most cooking was done in the study area using fire-wood and coals. The rest unclassified wastes included ashes, leaves, animal remains, nylons, etc.

In Ogbomoso North LGA, putrescible components, the largest one, constitute about two-fifth of the total wastes, metals had $16.6 \%$; paper $11.8 \%$; plastic $7.9 \%$; textile 5.9\%; glass 5.0\%; wood 3.9\%, nylon $4.9 \%$ while other unclassified components were $3.9 \%$. When compared with the values in the rural LGAs, the putrescible component was found to be lower. An earlier finding by [14] showed that the percent food component of wastes in Yola, a North-Eastern Nigerian city was 46 , the $40 \%$ value obtained in this urban LGA is therefore reasonable. The higher values of the metals and plastic components here, relative to the rural LGAs could be traced to some industrial activities taking place within the city. Similar reason could be given for high percent of paper component as products of educational institutions like the University, School of Nursing and Midwifery, Theological seminary, secondary and primary schools mostly located in the North LGA. The textile component is attributable to fashion and large population of people with high taste. The standard of living of the people in this LGA is considered high (urban LGA) as the wastes composed of new cartons, ragolis and other plastic containers, metallic cans and other fairly-used items. This finding agrees with the earlier discovery that the quantity of solid waste generated at a given period is an indirect reflection of life-

Table 3. Average composition of waste materials by mass in Ogbomosoland.

\begin{tabular}{|c|c|c|c|c|c|c|}
\hline Waste Materials & Ogbomoso North & Ogbomoso South & Oriire & Ogo Oluwa & Suurulere & Overall Mean \% Composition \\
\hline Paper & 11.8 & 4.0 & 2.4 & 1.8 & 2.0 & 4.4 \\
\hline Food & 40.1 & 51.7 & 78.3 & 85.7 & 86.3 & 68.4 \\
\hline Plastic & 7.8 & 4.8 & 2.4 & 2.1 & 2.2 & 3.9 \\
\hline Glass & 5.0 & 8.2 & 1.7 & 1.3 & 1.5 & 3.6 \\
\hline Metals & 16.6 & 13.4 & 2.6 & 1.6 & 1.9 & 7.2 \\
\hline Wood & 3.9 & 6.0 & 1.9 & 2.1 & 1.6 & 3.1 \\
\hline Textile & 5.9 & 7.9 & 4.0 & 3.1 & 2.4 & 4.7 \\
\hline Nylon & 4.9 & 2.1 & 4.3 & 1.8 & 1.6 & 2.9 \\
\hline Others & 3.9 & 2.2 & 2.3 & 0.3 & 0.6 & 1.9 \\
\hline
\end{tabular}


style in a community [15]. Most of these items could be recycled as against what obtained in the rural LGAs.

The components of waste in Ogbomoso South LGA are similar to those of North LGA basically due to the fact that the two are within the city. Food items constituted about $52 \%$ of the total wastes (Table 3 ). The selected dumpsite in this LGA located at Aarada market could have led to higher food waste components even when compared with that of Ogbomoso North. The market is known for buying and selling of food and agricultural products at cheaper prices. The lower percentage of paper could equally be deduced from similar reason, unlike in the R.A Bello street dumpsite of Ogbomoso North where many students reside. The metal components of the wastes of the two LGAs are about the same but are generally higher than those obtained in the suburb LGAs where automobile works and other related activities are less. Plastic components here were lesser than those obtained in the North LGA, probably due to the fact the Alata Plastic Store is located in the North LGA.

Putrescible materials constitute the highest waste in Oriire LGA as shown in Table 3. The higher values of food items than what obtained in the city LGAs could be attributed to heavy agricultural activities taking place in the LGA. The paper, plastic, glass, metal and wood components were however of lower values when compared with the ones within the city. Residents of the villages use less of these items. Broken calabashes, worn and torn rags, baskets and mats dominated the waste components. These are pointers to the fact that the income levels of the residents are lower than those of LGAs within the city. Similar to what obtains in Oriire and Suurulere LGAs, the food components have the highest mass. These bio-degradable materials constitute about $86 \%$ of the total waste being generated in this LGA. Other components with $4 \%$ or less include paper, plastic, glass, metals, wood and textile. The lower standard of living of the residents perhaps explains these compositions. Less educational and industrial activities in the area could have led to the smaller quantities of paper, plastic, glass and metals in the waste.

The composition of wastes in Suurulere LGA was similar to those of Oriire and Ogo Oluwa LGAs except for the general lower values of paper, wood and textile. In one of the selected dumpsites that were close to a motor-park, the quantities of paper, wood and textile being disposed of were insignificant. The food/bio-degradable component was however very high in all the dumpsites considered. This could be due to several commercial activities and residential houses around the dumpsite. The glass component in the waste (1.5\%) exceeded those found in Ogo Oluwa LGA (1.3\%) probably owing to the fact that the Suurulere dumpsite is surrounded by more residents with louver buildings and glasswares than those of Ogo Oluwa.

The overall average composition of wastes in the study area (Table 3) corroborates an earlier finding of [16] about the putrescible materials being the highest in wastes of Ibadan city, south-western Nigeria. It is however observed that wastes in Ogbomosoland still have higher organic materials than those in Ibadan, perhaps because of the latter being more urbanized. Wastes composition in developed countries like the United States of America and France have paper and textile as dominating materials $([4,11,12,16,17]$,$) . This is in contrast with$ the food items leading in the third world countries like the study area.

\subsection{Waste Density}

The summary of results of the measured densities of wastes in the 25 selected dumpsites in the study area is as presented in Table 4. The wastes from Oriire had the highest density of $490.4 \mathrm{~kg} / \mathrm{m}^{3}$ while those of Ogbomoso South had least value of $397.8 \mathrm{~kg} / \mathrm{m}^{3}$. The result shows that rural areas generate denser wastes when compared with the urban centers. This may be attributed to cartons, tins and other light-weight packaging materials dominating urban wastes in contrast with bulky items in the rural dumpsites [18]. The overall average waste density for the study area was found to be $438.1 \mathrm{~kg} / \mathrm{m}^{3}$. The finding is in line with a previous report by [19] that puts the waste density of a tropical country as $400 \mathrm{~kg} / \mathrm{m}^{3}$. Waste density is relevant in predicting the total amount of wastes generation per head, which serves as a useful input data in the waste planning and control system. It is noteworthy that since most organic wastes possess higher water content, the denser the waste the higher the leachate generation rate. The study area is therefore found prone to leachate pollution emanating from the dumpsites.

\section{Conclusions}

The denser biodegradable component was about 7 in 10

Table 4. The Average waste density in Ogbomosoland.

\begin{tabular}{cc}
\hline Local Government Area & Average waste density $\mathrm{kg} / \mathrm{m}^{3}$ \\
\hline Ogbomoso North & 403.0 \\
Ogbomoso South & 397.8 \\
Oriire & 490.4 \\
Ogo Oluwa & 448.3 \\
Suurulere & 451.1 \\
\hline
\end{tabular}

Overall average waste density $438.1 \mathrm{~kg} / \mathrm{m}^{3}$. 
of total wastes which could actually produce leachates which threaten the water resources of the area. The composition of wastes from R.A. Bello Streets, Town planning, showed presence of new cartons, ragolis containers and other fairly-used items suggesting a high standard of living in the urban LGAs. On the other hand, dumpsites like Laka Abogunde, Ita-Alasa, Aarada etc., have rags, baskets, calabashes and completely worn-out items, all pointing to a standard of living which is below the average. The higher the income, the lighter the waste and the lesser the water pollution risks.

\section{References}

[1] IHSE, "Biomedical Waste Management in Ibadan, Nigeria,” A Biomedical Waste Profile on Ibadan, 1999, p. 23.

[2] M. K. C. Sridhar, "Nature of Solid Wastes and Their Management," A Paper Presented at a one Day Seminar Organized by NINNAFEH, Ibadan, 2000, p. 2.

[3] O. A. Agbede, "Groundwater Pollution Levels in Nigeria," Proceedings of 20th WEDC Conference, Sri Lanka Colombo, 1994, p. 3.

[4] R. Taylor and A. Allen, "Waste Disposal and Landfill: Information Needs,” Accessed on 26 March 2007, pp. 1-8. http://www.google.Taylor

[5] FEPA, “5.1.8 National Environmental Protection (Effluent Limitation) Regulation 1991: 5.1.9 National Environmental Protection (Pollution Abatement in Industries and Faculties Generating Waste Regulation 1991),” Federal Environmental Protection Agency, Lagos, 1991, pp. 15B-31B.

[6] A. Fantola, "Introduction to Solid Waste Management Engineering,” Bibis Press, Ibadan, 1997, pp. 25-30.

[7] G. Tchobanoglous, H. Theisen and S. Vigil, "Integrated Solid Waste Management Engineering Principles and Management Issues,” McGraw-Hill, New York, 1993, p. 949.

[8] M. Ali, A. Cotton and K. Westlake, "Down to Earth: Solid Waste Disposal for Low-Income Countries,”
WEDC (Loughborough), 1999, p. 111.

[9] Microsoft Encarta Reference Library, "Solid Waste Disposal,” Microsoft Corporation’s Encarta Software, 2007, p. 2.

[10] USEPA, Environmental Protection Agency, Office of Solid Waste-Home Page, 2001, Accessed 20 April 20004. http:epa.gov/enviroed/eedefined.html.

[11] OECD, "Environmental Data," Organization for Economic Cooperation and Development Compendium, Paris, 1997, pp. 11-19.

[12] F. Attahi, “Abidjan, Cote Divoire (Chapter 2),” In: A.G. Onibokun, Ed., Managing the Monster: Urban Waste and Governance in Africa, IDRC, 1999, pp. 11-48.

[13] A. Y. Sangodoyin, "Consideration on Contamination of Groundwater by Waste Disposal System in Nigeria,” Environmental Technology, Vol. 14, No. 10, 1993, pp. 957964. .doi:10.1080/09593339309385370

[14] H. Nuhu, "An Assessment of Solid Waste Recovery and Utilization: A Case Study of Adamawa State,” An Unpublished M.Sc Project Report Submitted to the Department of Agricultural and Environmental Engineering, University of Ibadan, Ibadan, 2009, pp. 35-43.

[15] A. Y. Sangodoyin, "Ground and Surface Water Pollution by Open Dump in Ibadan, Nigeria,” Discovery and Innovation, Vol. 2, No. 1, 1991, pp. 37-43.

[16] A. Onibokun and A. J. Kumuyi, "Ibadan, Nigeria (chapter 3),” In: A.G. Onibokun, Ed., Managing the Monster: Urban Waste and Governance in Africa, IDRC, 1999, pp 49-100.

[17] C. Lusugga and J. M. Kironde, "Dar es Salaam, Tanzania,” In: A. G. Onibokun, Ed., Managing the Monster: Urban Waste and Governance in Africa, IDRC, 1999, pp. 131-172.

[18] S. O. Ojoawo, "Management of Leachate Pollution in Ogbomosoland South-Western Nigeria," Ph.D Thesis, Faculty of Technology, University of Ibadan, Nigeria, 2009, pp. 113-117.

[19] S. Cairncross and R. G. Feachem, "Environmental Health Engineering in the Tropics: An Introductory Text,” 2nd Edition, John Wiley, England, 1997, pp. 35-73. 